\title{
Assessing the Reading and Writing Skills of A1 Learners through the Application of Differentiated Instruction and the Use of Portfolios: A Case Study
}

\author{
American Journal of Education and \\ Learning \\ Vol. 5, No. 2, 159-174, 2020 \\ e-ISSN:2518-6647

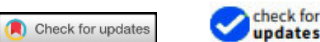

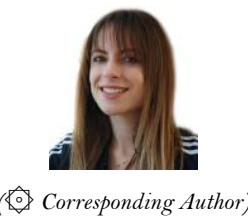

Corresponding Author

\author{
iD Aphrodite Didachou ${ }^{10 \%}$
} Makrina Zafiri

Department of English Language and Literature, MA in the Teaching of English as a Foreign/ International Language, English Language Instructor at a Private Language Institute, Greece. Email:aphroditedidachou@gmail.com Tel:00306985734020

'Aristotle University of Thessaloniki, Center of Foreign Languages, Academic Associate at the Hellenic Open University, Teacher Trainer at the Greek National Training Center of ASPAITE in Thessaloniki, Greece.

Email:m_nzafiri@yahoo.gr Tel:00306934118149

\section{ABSTRACT}

The main purposes that have triggered the present research are the potential benefits of implementing portfolios in a foreign language A1 class of students, as an alternative means of assessment. A case study was conducted in a Private Language Institute which examined the contribution of the portfolio in enhancing writing and reading skills. Alternative assessment, which is process oriented and is also an interactive and learner centered process, was expected to lead to increased motivation, learner autonomy and consequently to improved reading and writing performance (Burner, 2014). This research aimed at investigating how two groups of students, one of which formed the experimental group and was taught through differentiated instruction and the other which comprised the control group and was taught through the use of conventional books and materials which were used in the Private Language School, perceived and responded to the language goals. Feedback on portfolios aimed at demonstrating students' strengths and weaknesses and encouraged them to learn by moving away from traditional "paper and pencil" tests (Smith, 1996). Although formative assessment lacks the status given by parents or teachers, compared to a grade, it may be more suitable in selecting evidence of knowledge, especially the ability of students to perform certain tasks. In this procedure, not only will students have to evaluate their own work, but the teachers will also be required to reflect on her practices and choices for future development.

Keywords: Alternative assessment, Formative assessment, Portfolios, Private language institute, Reading, Writing.

DOI: $10.20448 / 804.5 .2 .159 .174$

Citation | Aphrodite Didachou; Makrina Zafiri (2020). Assessing the Reading and Writing Skills of A1 Learners through the Application of Differentiated Instruction and the Use of Portfolios: A Case Study. American Journal of Education and Learning, 5(2): 159-174.

Copyright: This work is licensed under a Creative Commons Attribution 3.0 License

Funding: This study received no specific financial support.

Competing Interests: The authors declare that they have no competing interests.

History: Received: 10 August 2020/ Revised: 16 September 2020/ Accepted: 30 September 2020/ Published: 14 October 2020

Publisher: Online Science Publishing 


\section{Highlights of this paper}

- Due to limitations in the traditional form of assessment and the shift towards a more student - centered approach, alternative assessment is proposed.

- Evaluating the integration of skills and the students' performance in a meaningful way.

- Enhancing the participation and independence of students.

\section{INTRODUCTION}

Theories on second language teaching and learning have changed significantly over the years. At first, foreign languages were taught through the application of the Grammar Translation Method and it was believed that knowledge of grammar or the ability to write and read were sufficient to communicate effectively with others Larsen-Freeman and Freeman (2008). Little attention was paid to speaking or listening skills, a perspective that has changed. Nowadays, the need to use all four skills successfully has been acknowledged and this shift of focus has led to the development of proficiency scales that can be used in all contexts for either instructional or evaluation purposes. Therefore, the Common European Framework of Reference, which is abbreviated to the CEFR, was first designed by the Council of Europe in 2001 to provide insights on the different levels that a learner can attain.

To begin with, the CEFR functions as a tool that provides a common basis for teachers or stakeholders to describe the objectives, the content and the methods used in language teaching and learning (Council of Europe, 2001). It seems that, even amongst teachers of the same language there can be various opinions on what is meant by the different terms used. Thus, the CEFR has become a common guideline in describing definitions and it has been used for different reasons as well, such as evaluating students' needs, developing materials or even courses. It is also used to develop continuous and self - assessment tools to test the students' ability to perform skills in the foreign language.

As exemplified by North (2014) the CEFR comprises a scheme for analyzing what is required in learning or in language use, setting a practical tool that can help teachers recognize even the slightest achievement in language learning rather than a set of rigorous rules to which one has to adhere to. Hence, it is used to talk about language levels reliably since it introduces a framework that determines the objectives for what students should learn, so that the target language can be used effectively. It can be useful not only to teachers, but also to school directors, teacher trainers and proficient learners. By using the CEFR one can take account of the fact that speakers can understand more than what they are able to produce, by describing language proficiency separately in relation to reception, production and interaction.

What is more, as a common framework of reference, the CEFR does not tell practitioners what to do or how to act during a lesson. It is neutral and thus it is possible to situate any style of instruction or methodology. It is based on the process of mastering an unknown language, using descriptors for each competence which was created without reference to any specific language. The CEFR enables students to say where they are at a specific point in time, which means that it is not a description that implies the point where the learners are supposed to be (North., 2007). The descriptors are presented in a positive manner a feature that might encourage teachers to focus on the advantages of the students' performance and provide positive feedback that may result in building their students' confidence.

\subsection{The CEFR Concerning A1 Learners}

The CEFR advocates that learning a language at a very young age makes the process of learning easier (Krashen, 1982) and it is believed that the earlier a child is exposed to a target language, the better. Because of this exposure, learners will not only develop their competence, but will also create a sense of belonging to a 
multicultural society. Feelings of prejudice and discrimination will be eliminated a fact which might motivate students to learn more foreign languages in the future (Council of Europe, 2001).

According to the descriptive parameters, introduced by Woodward (2001) which are also included in Sifakis, Georgountzou, and Hill (2004) the students who are selected to be the focus of this study and to experience alternative assessment, comprise a class which can be defined as a foreign language class (EFL). The research is carried out at a Private Language Institute and the class consists of seven monolingual eight and nine - year old students (two boys and five girls), who attend the third and fourth grade of public primary school. These students, are in line with the Common European Framework (Council of Europe, 2001) and can be characterized as being at an A1 'Breakthrough' level.

Level A1 (Breakthrough) corresponds to basic users of the language who are able to communicate in familiar situations with commonly used expressions and everyday vocabulary. In particular, the Council of Europe (2001) specifies that the students can interpret everyday expressions as well as simple phrases to meet their basic needs. The students are able to introduce themselves and others and can discuss personal details such as the place they live, things they have and describe people they know. Interaction is feasible provided that the interlocutor is prepared to cooperate by speaking slowly, clearly and in a simple manner. The aforementioned descriptors remain the same even though the descriptor scales had been adapted in 2018.

\subsection{English Language Portfolios (ELP)}

It is evident that, both the Common European Framework of Reference and its companion which is the European Language Portfolio (ELP) promote a student self - assessment approach. Language learning is considered to be a lifelong process and for this reason the CEFR values the development of autonomous students, because the moment that teaching is completed, further learning, which occurs, has to be autonomous. Autonomy refers to the students' ability to take control over their own learning as illustrated by Benson (2011) and it is exemplified that some students develop autonomy by themselves, while others need to be guided. Students whose experience is limited to traditional instruction will most probably not be able, for example, to assess themselves accurately. Thus, this is a process that has to be mediated by the teacher, involving considerations of the contents, the methods used, the purposes, and the final outcome.

Portfolio assessment has been developed in order to enable instruction in a way that can encourage learners to take risks and responsibility over their own learning (Ekbatani, 2000). The Council of Europe has developed three versions of European Language Portfolios that address primary school, secondary school and young adult life. Each one consists of three components: Firstly, a language passport which presents the students' language profile, an overview of proficiency level defined in terms of skills and reference levels as described in the Common European Framework. Secondly, a language biography that aims at encouraging the learner to reflect on his or her learning (Little, 2011) and finally a dossier including a selection of pieces of work which best represent the owner's judgments on L2 capacities (Council of Europe, 2001).

\subsection{The Purpose of the Research}

The form of assessment used, as a means for gathering information about the students' performance, is an essential component of the learning and teaching process. The form of assessment used for this purpose has been the traditional "paper-and-pencil" test so far. However, details about the process of learning or about important information on the students' attitudes, motivation, unique characteristics or preferred strategies cannot be collected through conventional methods Genesee and Hamayan (1994). Thus, due to limitations in the traditional form of 
assessment and the shift towards a more student - centered approach, alternative assessment is proposed.

The teachers' aims were to improve the students' achievement in all four skills (general aim) by selecting evidence of their progress especially in reading and writing (specific aim), and at the same time. to form a positive attitude towards learning and testing. The research hypothesis of this paper is that portfolio implementation is more beneficial to the development of young students than trational foreign language assessment. The teachers intended to design and introduce a model that can be used by the private language institute as proof of the quality of work which is done with the students. To these purposes, the research is organized according to 3 research questions that are posed andanalyzed in this paper. The research questions are the following;

- Are portfolios effective assessment tools?

- What factors play an important role in assessment?

- How does the application of portfolios enhance differentiated instruction?

\section{METHOD}

\subsection{The Learners' Profiles}

The students' learning profile is an "umbrella term" used to identify the distinct ways that a student receives and perceives information (Santangelo \& Tomlinson, 2012). These various ways of learning, referred to as multiple intelligences (Gardner, 1993) depend on the unique characteristics of each student's knowledge which, in turn, leads to successful differentiated instruction and then to an increased learning potential (Aliakbari \& Haghighi, 2014).

The class, which is conducted at a Foreign Language Institute (frontistirio), consists of seven monolingual young students, five girls and two boys, aged $8-9$, who all attend the third class of a Greek state, primary school. They are all speakers of Greek, whose contact with the target language only takes place inside the classroom, or from their exposure to the target language through the television, through songs or through videos on the Internet. The teachers who are also the researchers know the participants for approximately two years and are deeply aware of their strengths and weaknesses.

These students could best be described as A1 'Breakthrough', according to the Common European Framework of References (CEFR). Most of the students do not face any serious problems, concerning their level of proficiency. However, there are two students who seem to develop (linguistically) at a slower pace compared to the rest of their classmates. Scott and Ytreberg (1990) indicate that it is possible for some individuals to develop earlier than others, while others develop later or gradually. To be more specific, there are two girls who have some subtle learning disabilities that mostly affect their long - term memory and interfere with their ability to read and write. One is easily distracted and has a limited attention span and the other finds it difficult to pronounce the words when reading a text. Both become demotivated when they face these difficulties (Cameron, 2001). These have only been detected by the teacher and the students have not received a formal evaluation yet. As a result, due to differences in aptitude, personality and learning strategies, the class can be viewed, in a sense, as a mixed - ability one, since mixed learning styles are exhibited. Despite this, the class does not contain elements of other cultures as happens with most Greek classes of Foreign Language Institutes nowadays.

According to DeKeyser (2012) one of the most important characteristics which affect second language acquisition, or foreign language learning, is motivation or lack of it. These participants/students enjoy learning the English language and they are probably highly motivated as they always seem eager to participate in the lesson. The portfolio will thus attempt to provide an individual profile of each student, by collecting data such as their learning styles, their personalities, their abilities, etc., in order to help them develop. As we see from the Language 
Biography in their Portfolios, their major goal is to succeed in the B2 exam in the future. Another goal that was also included by most students was the desire to communicate fluently when travelling abroad.

In addition, these students have never been exposed to alternative forms of assessment and lack of prior experience might be discouraging at first. Most of the students feel nervous before writing a conventional test or even before their dictation, and the issue of anxiety has been discussed several times in the class. Due to this, the teachers tried to avoid terms such as testing, evaluating, etc. In an attempt to make them feel relaxed and to help them to understand that this can be an entertaining process.

\subsection{Research Methodology}

The teachers/researchers conducted a case study research to observe and collect information upon the students' progress during a specific period of time (Swanborn, 2010). According to Cohen, Manion, and Morisson (2007) a case study is illustrated as "a unique example of real people in real situations, enabling readers to understand ideas more clearly than simply presenting them with abstract theories or principles". This research was conducted in a natural setting, and it is expected that its results will shed light upon the research questions which were set earlier.

What is more, this research can be characterized as an action research, because it allowed the two teachers to become researchers of their own situation so as "to gain a deeper understanding of their practices, to reflect and to improve them" (Frost, 2002). Through action research the teachers may also find solutions to problems that the specific group of students face (Stringer, 2007). To this purpose, students of two groups of the same grade, language level and age will constitute the control and the experimental group. Students of the experimental group will be provided with differentiated instruction and pre - designed material concerning alternative assessment, and the control group will respectively continue with the coursebook which they are using. In the latter case, the teachers will follow a more conservative approach to teaching and testing which has always been applied in this foreign language institute.

In a nutshell, alternative assessment may lead to increased motivation, learner autonomy and to improved reading and writing performance (Burner, 2014). The aim of this particular research was to investigate how the one group, taught through differentiated instruction (followed by the use of a portfolio), and the other group through the conventional book which was taught in the private language institute, will perceive and respond to the goals set. Feedback on portfolios will be expected to demonstrate students' strengths and weaknesses in a way that learning will encourage them to move away from traditional paper and pen tests (Smith, 1996). Although formative assessment lacks the status given by stakeholders, compared to a grade, it may provide evidence of the abilities of students to perform certain skills, especially in terms of reading and writing. Not only will students evaluate their own work, but the teachers will also reflect on their own practices for future adaptation and development.

\subsection{Research Design \\ 2.3.1 Planning of the Portfolio.}

At the beginning the aims were specified. The main intention being initially to improve students' achievement in all four skills (general aim) by selecting evidence of their progress especially in reading and writing (specific aim), and secondly to help students form a positive attitude towards learning and testing. These aims were then classified into objectives. Setting objectives offered a sense of achievement to the students by completing one short term goal at a time. This usually leads to the formation of autonomous students (Benson, 2011) who will be introduced to ideas such as organizing, selecting and reflecting. In this way the teachers were able to monitor students' work and to acquire tangible evidence of the students' strengths and weaknesses. The aforementioned 
also gave teachers the opportunity to evaluate their own work and to modify their teaching techniques (if necessary).

Moreover, the rationale behind the teachers' choices lay in their wish to assess whether there will be a significant improvement on the part of the students, to prove that they will apply the knowledge gained and to avoid the errors that they made in their initial entries. There is an overall intention to follow a more processoriented instruction rather than a product oriented one to which students have been used to. Therefore, the writing process took place in the class and followed the recursive character of writing by promoting, as Zamel (1982) stated, drafting, editing, and redrafting. A writer - based approach was supported, as writing is believed to be a creative act of discovery that promotes personal expression with minimal teacher intervention (Hyland, 2003). Thus, the reading input was not there for imitation purposes but rather to be treated as a model to organize ideas (Grabe \& Kaplan, 1996). Also, all lesson plans involved students in a warmup activity to introduce them to the topic of the lesson and encourage them to participate and generate ideas through brainstorming.

The portfolio consisted of the following components: namely the Language Biography, the Language Passport and the Dossier. These had been adjusted to the needs of this group o the students so that the portfolio could meet their needs. In order to become aware of the whole procedure and the role of the ELP, the parts of the Language Biography and Passport had also been translated in the L1 and students were encouraged to write their experiences and ambitions considering the target language in Greek.

At first, the teachers/researchers asked the owner of the foreign language institute for permission to apply alternative assessment in the class for the completion of this research. It was arranged to teach the experimental group on Fridays. Parents were also informed, through a letter, about the new practice which would be adopted. The students were initially informed about the portfolio at the beginning of the school year. The teachers/researchers explained the meaning of the word portfolio. At that point, the students seemed to be terrified of this new notion and the extra work that they would have to do and they were filled with anxiety. It is worth mentioning that these students always express their anxiety before a test or even before they write their dictation, and the teachers/researchers were aware of these feelings and expected such reactions from them. Then, the procedure was described to the students and so was its purpose. Students welcomed the idea with enthusiasm once they were reassured that this would be a new way to "test them without testing them". They liked the idea of having their own files, very much, and they became excited when the teachers informed them that they could draw or decorate their portfolios if they wished.

Moreover, the teachers/researchers distributed the guidelines and mentioned the importance of including a cover letter, a table of contents, core and optional items, as well as reflections of each item, and of the whole portfolio. The optional entries in the portfolio were requested so that a sense of ownership could be promoted. The teachers/researchers stated that the completion of the portfolio carried 30 per cent of their final grade. Their evaluation was based on certain criteria, which they will receive in writing, for their convenience, as is shown in the tables which follow:

Table-1. Overall Assessment Criteria for Students' Grade.

\begin{tabular}{|c|c|c|c|}
\hline Topics & Grade \% & Student Evaluation & Teacher Evaluation \\
\hline Oral Participation & 30 & & \\
\hline Portfolio & 30 & & \\
\hline Final Test & 10 & & \\
\hline Homework & 15 & & \\
\hline Progress made & 15 & & \\
\hline Total & 100 & & \\
\hline
\end{tabular}


Table-2.Teacher's Criteria to Assess Written Work in Portfolios.

\begin{tabular}{lc}
\hline Criteria & Grade \\
\hline 1. Use of new vocabulary. & $/ \mathbf{1 0}$ \\
2. Correct subject - verb agreement. & $/ 10$ \\
3. Use of capitals to start sentences. & $/ 10$ \\
4. Use of periods and question marks. & $/ 10$ \\
5. Correct spelling. & $/ 10$ \\
6. Ability to write complete sentences. & $/ 10$ \\
7. Neat handwriting. & $/ 10$ \\
8. Good use of grammar. & $/ 10$ \\
9. Ability to write a short paragraph. & $/ 10$ \\
10. The piece of work makes sense. & $/ 10$ \\
Total mark. & $/ 10$ \\
\hline
\end{tabular}

The small size of the Portfolio offered a format that could easily be used and stored by the students themselves. It was specially designed to meet the young students' needs, and its form was quite simplified but still quite challenging. To an adult's eye, the numerous pictures incorporated may seem remarkably simple, but to young students they were very attractive as they captured their imagination and triggered their motivation (Schneider \& Lenz, 2001). The portfolios were kept at the language school, on shelves, inside the classroom. They consisted of folders, and students could decorate them if they wished. Thus, some students drew pictures according to the content of their texts or placed some stickers.

Last but not least, according to Williams (2000) certain qualities such as objectivity, validity, reliability and practicality are considered fundamental for the implementation of alternative assessment, otherwise teachers' subjectivity is maximized. Thus, considering the aforementioned, the teachers/researchers shared the rating scales and the evaluation criteria that had been planned. Also, the expected aims were explained to the students so that the degree of reliability could be increased, as depicted by MosKal (2003). Hence, the students' portfolios were not only relevant to what they had already been taught, ensuring good face validity, but they were also reliable, as positive wash back could be acquired by the teachers / researchers from their application.

\subsubsection{Implementation of Portfolio Assessment}

At first, students completed their personal details and then filled in the Language Biography. The latter consisted of two parts which were labeled as a) Languages I know and b) How do I learn the English Language. In the first part the students informed the teachers/researchers about the number of languages they speak and for how long they have been learning these languages. In the second part, they discussed facts concerning their English lessons at the Language Institute (e.g. what they liked doing during the lesson) and in the third part they set their goals.

Furthermore, the teachers/researchers invited the students to engage in the first core item which asked them to complete information about themselves. Due to their low level of proficiency, students were only currently starting to write short sentences and the aim of this task was to involve them in writing full sentences. The teachers/researchers facilitated the process by answering all their questions and by guiding them. Their answers were expected to be used as notes for the production of a short paragraph, in Activity 2, which was - basically their next writing stage. Then the students were asked to revise their paragraph before the teachers/researchers checked it for any errors.

Hence, process writing was essential in alternative assessment and that is why the teachers/researchers asked the students to rewrite their paragraphs, if this was deemed necessary, following the teachers'/researchers' feedback. This process was repeated at every core item and was based on Swain (2012) concept that reflection 
enables one to evaluate the experience of the procedure, learn from errors, revise and then plan for future success. Errors were underlined and asked to be corrected by the students themselves in an effort to guide them towards self - reflection, and then the final draft was marked according to the scoring sheet. After that, each student completed a self - assessment form, which was provided in the section labeled "reflection" at the end of their portfolio. The items which were included in the assessment forms contained issues such as the degree of difficulty, their involvement in the task, etc. They were all translated in Greek and were simple enough for them to comprehend.

In the second entry, the students were asked to follow a similar process to the first one the only difference being that they should write about their friend, after they had answered some questions first. The teachers' /researchers' aim was to facilitate their students less than in the first task so that they could develop into autonomous learners, especially now that they were familiar with this type of activity, and were thus more confident. At the end of the lessons, the students were encouraged to present themselves or their friends so as to practice their presentation skills (core items 1 and 2).

The third entry engages students in describing their neighborhood. At first, they reviewed vocabulary and learned some additional words. Then, they matched the words to the picture which they were shown and were asked to use them along with the notes in activity 2 to describe what they do in their neighborhood. This was the preparatory stage before they wrote a short paragraph about the neighborhood they lived in. A drawing was also required to assist writing and to make the whole process more appealing. The focus here was on specific language forms, for example the use of the present simple, and on writing short sentences which they presented in the class.

In the fourth entry, students listened to a popular song (Head, shoulders, knees and toes) and were encouraged to sing along and point at the part of the body described. After this warm - up activity they matched the pictures to the words. In activity 3 students were expected to draw a monster and to write a paragraph about it, thus practicing the verb "have got", in a fun manner. In the end, they presented and showed their monster to the rest of their classmates.

In the fifth lesson, students revised the vocabulary which concerned animals. They wrote one animal for each letter of the alphabet and then discussed the words in activity 2. Several animals and facts about them were provided in a table to exemplify what information was expected to be written in Activity 4 . In the sixth lesson, the teachers/researchers engaged students in listening to a song. Before that, background knowledge was activated through the descriptionof two pictures. Then, they listened to the song twice and were asked to complete a list with food that they could recall from the song (hard - focus listening). The students who were not able to complete their lists were encouraged to cooperate with the person sitting next to them. The following two activities prepared them for the final activity which was to describe their favourite animal.

In the seventh lesson, students read a story with the teachers/researchers. They were shown the pictures and were expected to keep notes by completing the chart which had been given to them in their sheets. Students could cooperate if they wished to, so that even weaker students would be able to do the activity. After that, they were asked to retell the story in their own words by looking at their notes. In this way, the teachers/researchers verified that all students kept notes and that they could continue with writing a summary of the story.

In the final lesson, students were requested to describe their room. At first, the students looked at the pictures in Activity 1 and answered to the teachers'/researchers' questions. They were introduced to new vocabulary and answered questions about their bedroom. What is more, they read a sample description of a bedroom and told the teachers/researchers in which way their bedroom was different than the one they had seen in the picture. In activity 3 they completed a chart which was comprised of two lists. In the first list they wrote the objects which they had in 
their bedroom and in the second list they wrote what they do not have. The aim of this activity was to collect information and plan their ideas so as to facilitate their writing process in Activity 4. The students shared what they had written with their classmates once a week. Through this process, students practiced their reading and also had an idea of where their strengths lay in relation to their classmates' strengths.

\section{RESULTS}

\subsection{Statistics and Data Analysis}

The teachers/ researchers distributed the first questionnaire after the students had grasped the general idea and purpose of portfolio assessment and prior to the intervention. They were also given a second questionnaire which was carried out after the completion of the portfolios so that both results could be compared. The teachers/researchers opted for the use of the Greek versions in an attempt to minimize the level of difficulty of the questionnaires and to ensure that all students would comprehend and complete them successfully. The language used in the class was Greek and the teachers/researchers provided help when requested. Despite this, most of the students found it difficult to answer the open - ended questions and frequently asked the teachers/researchers what to write. Copies were distributed to all students of the experimental group and the findings indicated some useful informationwhich will be presented below.

First of all, the majority of the students stated that portfolio assessment would be a tiring procedure $(71,42 \%)$ that would make them feel more stressed $(85,71 \%)$ and that they would not enjoy the process $(71,42 \%)$ as shown in the graph.

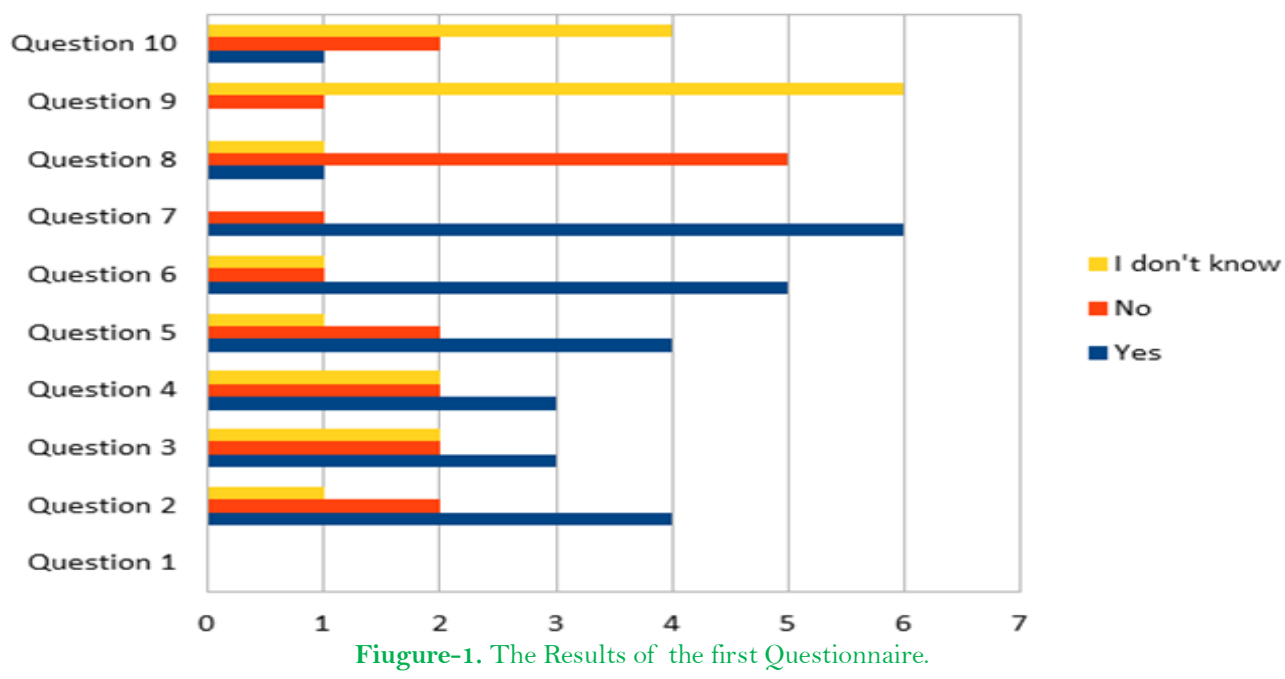

However, these initial concerns did not comply with the results of the second questionnaire in which $71,42 \%$ of students mentioned that this was neither a stressful nor a tiring procedure. Surprisingly, 57\% of the students deemed this as an enjoyable experience and $42,85 \%$ of the students mentioned that it was very enjoyable, while none had a negative attitude towards it. Furthermore, 71,42\% agreed and 28,57\% strongly agreed that portfolio assessment should be used next year too, as opposed to the first questionnaire in which they claimed that they did not really know what to answer, mostly due to their ignorance. What is more, the students' point of view on the educational value of the portfolio was generally confirmed in the second questionnaire with slight differences as depicted in the next graph. 


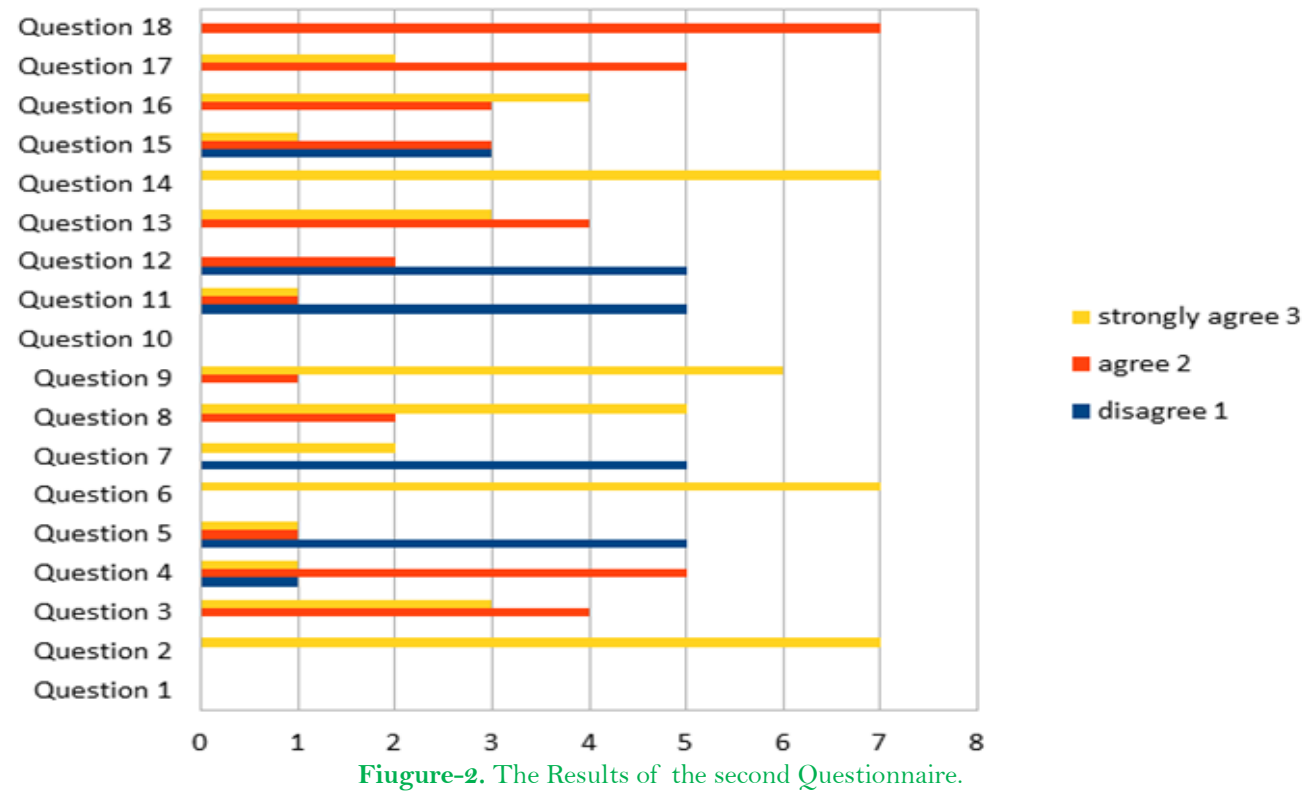

Moreover, the results of the research provided valuable evidence on how students experienced portfolio implementation and what they were able to do. In other words, the students' strengths and weaknesses were illustrated and they were able to familiarize themselves with alternative assessment even though their first reaction to the portfolio was not very positive. In addition, they acquired skills that encouraged them to take on more responsibility for their own learning by selecting their own optional entries which gave them a sense of independence and autonomy. By assuming responsibility over one's learning is - generally - considered to be a stepping stone in becoming an autonomous student as stated by McDonald and Boud (2003).

Overall, the whole process focused more on the learning process and the improvement of the students' performance rather than on receiving a better grade. Moreover, an enjoyable environment was established which was evident by the fact that students actively participated in the procedure, they took pride in their accomplishments and were more than eager to present their work to their classmates. The variety of writing tasks engaged students and helped them to develop their writing skills and to build their metacognitive awareness and strategies, in cases, such as, when pictures were used to infer the meaning of unknown words.

The students realized that writing is a recursive process (Zamel, 1982) and they progressively produced more than one drafts before their final product. At first, students were encouraged to edit their own work and were able to correct some cases in which they omitted pronouns. The teachers/researchers detected some syntactic and/or grammatical errors and provided extra feedback if the meaning was incomprehensible. The students were expected to use the teachers' comments and corrections in order to rewrite their piece of work. However, in the initial core items included in the portfolio only one student had rewritten his paragraph contrary to the end of the process in which all students had a draft and their final work. As a result, their outcomes were more successful than at the beginning. O'Leary (2007) states that assessment involves both the process and the outcome of learning which can enhance both learning experience and autonomy.

Generally, most students seemed to react in a positive manner towards alternative assessment as they were eager to participate in the lesson. The topics selected were closely related to their interests and their personal experience which resulted in triggering their attention and motivated the students to actively contribute to the lesson. Moreover, the lessons were designed on the basis of the recursive pre-, while-, and post- stages. Writing strategies like, drafting, self-correcting and redrafting were promoted by the tasks, which encouraged students to 
become autonomous learners (Benson, 2011).

Last but not least, it was evident that students of the experimental group outperformed the control group, when they wrote their final test as depicted in the graph below;

\section{Comparison of the Results}

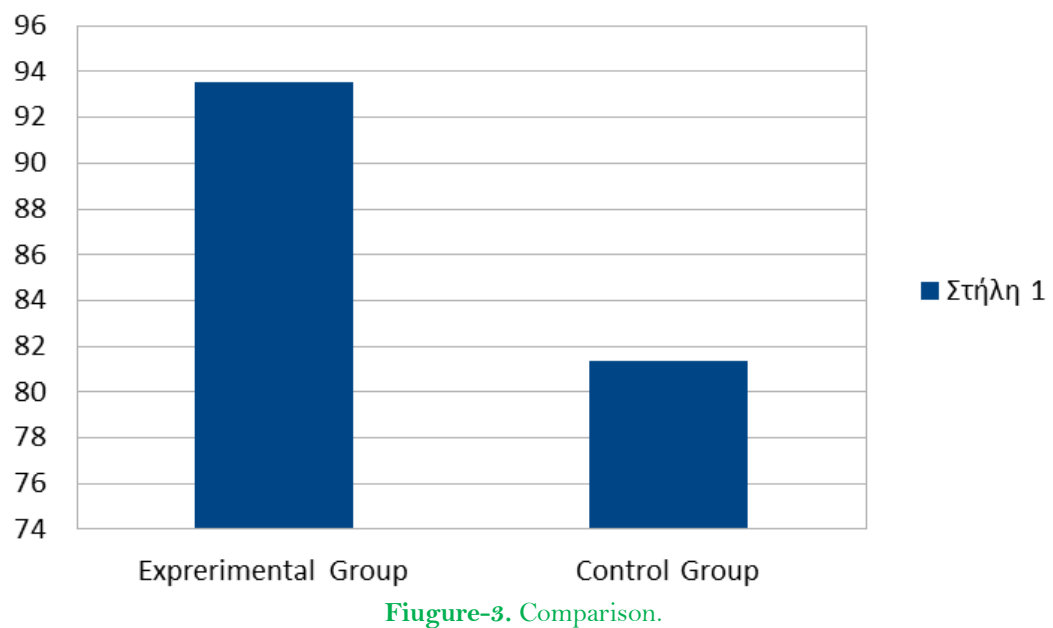

More specifically, the students of the experimental group wrote approximately $93,57 \%$ while the students' average percentage was $81,37 \%$ in the other group. This improvement in performance may be attributed to the fact that the students' self - awareness increased because of their reflection and because of the specific teaching intervention.

\subsection{Discussion}

Based on the aforementioned findings, it seems that the portfolio was successfully implemented in the foreign language class, as the students did not face any serious difficulties and they responded adequately to all the demands of the portfolio. All interested parties were provided with insight about the impact portfolios have on young students. The students proved their competence and their ability to achieve certain tasks, whereas the teachers were informed about what their students could actually do in the target language.

According to Tsagari (2005) the value of portfolio assessment lies in the reporting and pedagogical qualities it possesses and the extent to which these are combined. Hence, the portfolios designed for this teaching context indicated a combination of elements of the showcase and process portfolio. The portfolio was viewed as a vehicle to evaluate the integration of skills and the students' performance in real life situations and it became a vital component as it told the story of the students' achievements, skills and efforts, in general, by selecting, compiling, and displaying their work.

What is more, the results of the questionnaires provided the answers to the three research questions posed. More specifically, the first research question referred to the effectiveness of the ELP as an assessment tool. The findings from this research demonstrated the value of alternative assessment in enhancing reading and especially the writing skill through a variety of tasks in which students were engaged. Oracy skills were reinforced as well, so that meaning could also be constructed (see also Gee (2000)). Thus, the ability to integrate skills and the students' overall performance were also evaluated through portfolio implementation (Benson, 2011). Overall, the portfolio became a vital component in telling the story of the students' achievements, in presenting their skills and efforts, in selecting, compiling and displaying their work, all of which allowed the teachers to collect evidence of their 
students' strengths and weaknesses in the target language (Simon \& Forgette-Giroux, 2000).

Additionally, alternative assessment provided the students with the chance to assess themselves after self reflecting on every core item included. However, the researcher came to the conclusion that the majority of the students were lenient with themselves and even overestimated their performance when they self - evaluated their written product and their answers were not always relevant to the truth. They seemed to answer to what was considered appropriate or what would provide them with a better grade.

The second research question examined the factors that played a fundamental role in alternative assessment. To start with, the teachers'/researchers' initial concern was to form a friendly environment which was a prerequisite so that students could feel secure and confident in order to actively participate in the procedure as mentioned in the previous section. Enhancing the students' motivation was a challenging factor for the teacher as well, since it is one of the factors which can determine their success in learning a language (Ellis, 2000). Based on the information retrieved from the second questionnaire, it seems that most of the students were more motivated after the completion of the portfolios and the whole process was appealing to them. The teachers/researchers realized a gradual increase in their students' interest in actively participating in the lesson and it was a great satisfaction to them when they read (in the students' answers) that they were eager to create a portfolio the next year.

What is more, another important factor was the role that the teachers/researchers assumed. At first, it was quite necessary to familiarize these young students with the idea of creating a portfolio since they had no former experience. However, after a few lessons and writing activities, they received a minimum of teacher(s) intervention and were encouraged to follow their own path and become independent students. Thus, the teachers/researchers acted as mere facilitators in the process, by providing instructional support only when necessary, as suggested, and a learner - centered approach was opted for (Haradasht \& Aidinlou, 2016).

The third research question analysed the extent to which the application of the portfolio enhanced differentiated instruction (Hamayan, 1995). It is claimed that most classes are filled with students who have diverse abilities and needs. Hence, the teachers'/researchers' aims were to provide students with more opportunities and strategies to evolve to the best of their abilities. An excellent way of achieving this was by implementing portfolios in the class. Students had their voice heard when they reflected on their work and on how they learnt best. They played an active role in their - own - learning as they were responsible for meeting certain criteria which were preset. They exhibited their growth through a period of time allowing themselves to develop at their own pace and according to their particular needs.

Furthermore, the regular implementation of self-assessment checklists and being responsible for the collection of both core and optional items had a great effect on the students' sense of independence (Benson, 2011). A few of the students who were not eager, at first, to complete the checklists, started completing them with more enthusiasm and seemed to understand their importance. This was evident by the reasons which they gave in their questionnaires, after having reflected and selected their best pieces of work. Other essential factors that contributed to the development of learners' autonomy were their positive attitudes towards the process, their reflective stance that was enhanced, the interaction and collaboration between the students and the teacher. It is worth mentioning that the more autonomous a learner becomes the more opportunities he/ she has to achieve proficiency in the target language as stated by Dafei (2007) and this idea is congruent with the findings as writing improvement is in line with autonomy development.

The outcomes of the assessment process could be utilized for future improvement. It seems that there is a strong link between assessment and instruction. The results of the students' self-assessment offered the teachers/researchers valuable feedback which could be used to monitor and modify future instruction so as to affect 
student achievement. The information obtained from this research allows the teachers/researchers to recognize the current needs of students and to set new goals. More specifically, for this teaching context the teachers/researchers attempted to maximize the students' opportunities to improve their reading skills, in the future, by including more authentic texts to work with.

Overall, portfolio assessment meets the criteria of a qualitative research. The procedure followed and the materials used corresponded to the teaching goals set by the teachers/researchers and portfolios could be characterized as valid since they described the performance they intend to assess. In addition, the clear assessment criteria and marking schemes form a reliable method of assessing young students. Last but not least, the portfolios are almost always a fair method because they involve work over a period of time, allowing students to reflect on their choices and output.

\subsection{Limitations of the Study}

Regardless of the positive results drawn by the implementation of the portfolio, there were several limitations too. It appears that one teaching hour once a week was not enough to collect significant evidence of language development. Students worked at a different pace and a lot of explanation was required therefore most of the writing tasks were assigned as homework. What is more, if there had been more time, then the teachers/researchers would have incorporated more types of assessment like peer observation. This would support the notion that alternative assessment enhances a collaborative approach as suggested by Barootchi and Keshavarz (2002).

Additionally, the whole process was time - consuming for the teachers/researchers themselves, as not only did they have to assess the students' work but also to plan, collect and prepare appropriate material for students who are so young. This was too demanding as it was quite difficult to select authentic reading input for the development of their reading skills. As a result, more emphasis was given to their writing skills. More authentic elements (authentic input) would have increased the degree of objectivity of the input and they would have more beneficial wash back and wash forward effects (Hughes, 2003). Another difficulty that the teachers/researchers encountered was the setting of clear assessment criteria that would be apprehended by the young students.

Last but not least, as mentioned in the previous section the students' answers in the self-reflection sheets did not always comply with the teachers'/researchers' evaluation thus, the researchers were not sure whether the students' answers were true or whether they answered what would be pleasing to their ears. As for the assessment sheets, they were simplified enough for students to understand the meaning of the sentence, but occasionally they needed further instruction. This means that certain items should have been more concrete and should also have been formed in an even more simplified manner.

\subsection{Recommendations}

The results proved that the implementation of portfolios and self - assessment techniques should be established in both the private and the public sector in Greek schools, regardless of the limitations discussed in the previous section. In this way, students may become more autonomous (Benson, 2011) from a younger age, since they will take on more responsibility for their own learning, after continuous exposure to evaluation techniques. What is important for the teacher is a thorough understanding of the meaning of differentiated instruction (to adapt the lesson), which will provide opportunities for lifelong learning and educational development (Papaefthymiou - Lytra, 2014).

However, the ELP which was selected for this teaching context should be altered in some of its more 
problematic parts so that it can constitute a safe choice for the teacher to include it as an assessment tool in her class. Firstly, was quite obvious that the ELP had to be presented in the students' native language because of their low level of proficiency. Thus, the various guidelines and instructions of the portfolio were all translated in the Greek language. However, because of the students' young age a lot of elaboration was required and the teachers/researchers devoted a lot of time not only in translating the task sheets but also, in explaining the whole procedure orally. Therefore, the teachers/researchers need to strategically allocate time to assess the current organizational structure in the future, so that more time is left as productive teaching time. Simultaneously, students will most probably imitate their teachers' actions concerning time- and task - management, qualities that they ought to acquire. Portfolios will encourage students to stay organized by developing a filing system which reduces the time which is needed to try to find things, etc.

Furthermore, the open-ended questions which were included in the self-assessment questionnaire or in the Language Biography, should be made more specific in the future or should - perhaps - be erased, since they were abstract and students found them difficult to answer as mentioned. As for the Portfolio, students were engaged in selecting and organizing their work, but they were not involved in setting the format of their Dossier as this had already been prepared by their teacher for their convenience. However, as students progress and become more familiar with the idea of creating a portfolio they should be assigned with more responsibilities.

In addition, the positive findings of this research encourage further consideration and more investigation on alternative assessment (DeKeyser, 2012). Further research on the ELP might be valuable to teachers that seek to find new methods to increase student motivation and create an instructional basis upon which they will be able to strengthen their students' educational potential which will result in the enhancement of their communicative competence. Consequently, adequate time should be devoted to empirical testing and a longitudinal research should also be conducted to yield more reliable and valid results, as this was a small-scale research. Finally, it would be interesting if a similar research was conducted by a group of teachers in terms of validity and reliability.

\section{REFERENCES}

Aliakbari, M., \& Haghighi, J. K. (2014). Impact of differentiated instruction strategies and traditional - based instruction on the reading comprehension of Iranian EFL students. Research in Applied Linguistics, 5(1), 109-129.

Barootchi, N., \& Keshavarz, M. H. (2002). Assessment of achievement through portfolios and teacher-made tests. Educational Research, 44(3), 279-288. Available at: https://doi.org/10.1080/00131880210135313.

Benson, P. (2011). Teaching and researching autonomy in language learning. England New York: Longman.

Burner, T. (2014). The potential formative benefits of portfolio assessment in second and foreign language writing contexts: A review of the literature. Studies in Educational Evaluation, 43, 139-149. Available at: https://doi.org/10.1016/j.stueduc.2014.03.002.

Cameron, L. (2001). Teaching languages to young learners. Cambridge: Cambridge University Press.

Cohen, L., Manion, L., \& Morisson, K. (2007). Research methods in education (6th ed.). London: Routledge Falmer.

Council of Europe. (2001). Common european framework of reference for languages: Learning, teaching, assessment. Cambridge: Cambridge University Press.

Dafei, D. (2007). An exploration of the relationship between learner autonomy and English proficiency. Asian EFL Journal, 6(2), 1-23. Available at: https://doi.org/10.12973/jesr.2016.62.1.

DeKeyser, R. M. (2012). Age effects in second language learning. In Gass, S. \& Mackey, A. (Eds.), The Routledge handbook of second language acquisition (442 - 460 ed.). London: Routledge. 
Ekbatani, G. (2000). Moving toward learner-directed assessment. In Ekbatani, G. and Pierson, H., editors, 2000. Learnerdirected assessment in ESL (pp. 1-11). Mahwah, NJ: Erlbaum.

Ellis, G. (2000). Teaching English to young learners: Reflections on a decade(1990-2000). The British Council.

Frost, P. (2002). Principles of the action research cycle. In R. Ritchie, R. A. Pollard, P. Frost $\&$ T. Eaude (Eds), Action Research: A Guide for Teachers. Burning

Issues in Primary Education (3rd ed.). Birmingham: National Primary Trust.

Gardner, H. (1993). Multiple intelligences: The theory in practice. United States of America: Basic Books.

Gee, J. P. (2000). The new literacy studies, from 'socially situated' to the work of the social. In D.

Genesee, F., \& Hamayan, E. V. (1994). Classroom-based assessment. Iin Genesee, F. (ed.), Educating Second Language Children: The whole child, the whole Curriculum, the whole community (pp. 212-239). New York: Cambridge University Press.

Grabe, W., \& Kaplan, R. (1996). Theory and practice of writing: An applied linguistics perspective. London: Longman.

Hamayan, E. V. (1995). Approaches to alternative assessment. Annual Review of Applied Linguistics, 15, $212-226$.

Haradasht, M. A., \& Aidinlou, N. A. (2016). A case study on EFL classroom discourse. International Journal of Humanities and Cultural Studies (IJHCS) ISSN 2356-5926, 1(1), 1762-1770.

Hughes, A. (2003). Testing for language teachers. Cambridge: Cambridge University Press.

Hyland, K. (2003). Genre-based pedagogies: A social response to process. Journal of Second Language Writing, 12(1), $17-29$.

Krashen, S. D. (1982). Principles and practice in second language acquisition Oxford. England: Pergamon.

Larsen-Freeman, D., \& Freeman, D. (2008). Language moves: The place of "foreign" languages in classroom teaching and learning. Review of Research in Education, 32(1), 147-186. Available at: https://doi.org/10.3 102/0091732x07309426.

Little, D. (2011). The European language portfolio. A guide to the planning, implementation and evaluation of whole-school projects. European Centre for Modern Languages.

McDonald, B., \& Boud, D. (2003). The impact of self-assessment on achievement: The effects of self-assessment training on performance in external examinations. Assessment in Education: Principles, Policy \& Practice, $10(2), 209-220$. Available at: https://doi.org/10.1080/0969594032000121289.

MosKal, B. M. (2003). Recommendations for developing classroom performance assessments and scoring rubrics. Practical Assessment, Research \& Evaluation(8), 14.

North, B. (2014). The CEFR in practice (Vol. 4): Cambridge University Press.

North., B. (2007). The CEFR: Development, theoretical and practical issues. Babylonia, 1(7), 22-29.

O'Leary, C. (2007). Should learner autonomy be assessed? In M. Castillo, L. Cooker \& K. Irie (Eds.), Proceedings of the independent learning association 2007 Japan Conference: Exploring theory, enhancing practice: Autonomy across the disciplines. Japan: Kanda University of International Studies.

Papaefthymiou - Lytra, S. (2014). L2 lifelong learning/ use and new media pedagogies. Research Papers in Language Teaching $\Xi^{\circ}$ Learning, 5(1), 16-33.

Santangelo, T., \& Tomlinson, C. A. (2012). Teacher educators' perspectives and use of differentiated instruction practices: An exploratory investigation. Action in Teacher Education, 34(4), 309-327.

Schneider, G., \& Lenz, P. (2001). European language portfolio: A guide for developers. Strasbourg: Council of Europe.

Scott, W. A., \& Ytreberg, L. H. (1990). Teaching English to children. UK: Longman Group UK Limited.

Sifakis, N., Georgountzou, A., \& Hill, M. (2004). Language learning skills \& materials (Oracy and literacy) (Vol. 1). Patras: Hellenic Open University.

Simon, M., \& Forgette-Giroux, R. (2000). Impact of a content selection framework on portfolio assessment at the classroom level. Assessment in Education: Principles, Policy $\mathcal{F}^{\circ}$ Practice, 7(1), 83-100. Available at: https://doi.org/10.1080/713613325. 
Smith, K. (1996). Action research on the use of portfolio for assessing foreign language learners. IATEFL Testing Nerusletter, 1724.

Stringer, E. T. (2007). Action research. USA: Stage.

Swain, D. (2012). Changes in perspective teacher attitudes toward inclusion. Preventing School Failure: Alternative Education for Children and routh.

Swanborn, P. G. (2010). Case study research: What, why and how? India: Stage.

Tsagari, C. (2005). Portfolio assessment with EFL young learners in Greek state school. Paper presented at the In Serving TEA to Young Learners: Proceedings of the Conference on Testing Young Learners organized by the University of Cyprus, IATEFL and CyTEA.

Williams, J. (2000). Implementing portfolios and student - led conferences. ENC Focus.

Woodward, T. (2001). Planning lessons and courses: Designing sequences of work for the language classroom. Cambridge: Cambridge University Press.

Zamel, V. (1982). Writing: The process of discovering meaning. TESOL Quarterly, 16(2), 195-209. Available at: https://doi.org/10.2307/3586434. use of the content. Any queries should be directed to the corresponding author of the article. 